\title{
Eligibility criteria of Doctorate in Medicine (Medical Gastroenterology) - Is the change justified?
}

\author{
Tryambak Samanta $\cdot$ Sutapa Ganguly
}

Received: 25 April 2011 / Accepted: 23 May 2011 /Published online: 15 June 2011

(C) Indian Society of Gastroenterology 2011

\begin{abstract}
Eligibility criteria of Doctorate in Medicine (DM) in Medical Gastroenterology had been changed recently by Medical Council of India from MD/DNB in General Medicine and Pediatrics to only that of General Medicine. As DM (Pediatric Gastroenterology) has not come up in a big way in India, this will only lead to shortage of skilled manpower in near future in this emerging field. Enthusiastic pediatricians will also be reluctant to take the discipline, as DM degrees in other broad (adult) superspecialities are open to them.
\end{abstract}

Keywords Doctorate in Medicine (DM) - Medical Council of India (MCI) $\cdot$ Medical Gastroenterology

Eligibility criteria for admission to Doctorate in Medicine (DM) degree courses in Medical Gastroenterology were originally set by the Medical Council of India (MCI) as MD/ DNB in General Medicine or Pediatrics [1]. An amendment of July 21, 2009 deleted MD (Pediatrics) from these criteria [1]. Simultaneously, DM (Pediatric Gastroenterology) course was added in the list of MCI-approved DM courses, with eligibility criterion of MD (Pediatrics) degree.

Enlistment of DM (Pediatric Gastroenterology) in the list of approved courses is definitely commendable. However, this should not have led to the debarring of persons with MD (Pediatrics) degree from joining DM (Gastroenterology) courses because DM (Pediatric Gastroenterology) courses are still at an embryonic stage. To date, as per the MCI's official website (www.mciindia.org), no DM (Pediatric Gastroenterology) course has been approved [2].

In addition, surprisingly and somewhat inexplicably, MD (Pediatrics) degree continued to be retained among eligibility

T. Samanta $(\bowtie) \cdot$ S. Ganguly

Pediatric Gastroenterology Unit, Department of Pediatric

Medicine, Nilratan Sircar Medical College and Hospital,

Kolkata 700 014, India

e-mail: ts_ped@rediffmail.com criteria for DM (Cardiology) and DM (Nephrology), when DM (Pediatric Cardiology) and DM (Pediatric Nephrology) courses, respectively, were listed by the MCI [1]. The reason for following a different policy when DM (Pediatric Gastroenterology) was enlisted is not clear.

Pediatric Gastroenterology is an emerging field. A few seats every year all over India in the near future will be highly inadequate to meet the demand across the country. Moreover, it will not be possible to start new training courses in Pediatric Gastroenterology in the next 10-15 years, until a pool of trained pediatric gastroenterologists are available across the country. With the availability of training in other DM courses in broad (adult) superspecialties remaining open for pediatricians, the current restrictive criteria for admission to DM (Gastroenterology) may lead to fewer pediatricians taking up the field of Gastroenterology in the next few years.

We believe that, upon introduction of DM (Pediatric Gastroenterology) courses, persons with MD (Pediatrics) qualification should have continued to be eligible for DM (Gastroenterology) course, at least for a substantial overlap period. Once a sizeable number of pediatric gastroenterologists had become available across the country and the number of DM (Pediatric Gastroenterology) seats had increased to a modest extent, MD (Pediatrics) could have then been removed from the list of eligibility criteria for DM (Gastroenterology).

\section{References}

1. Medical Council of India. Rules and Regulation, Post Graduate Medical Education Regulations (2000). Available from: URL: http:// www.mciindia.org/RulesandRegulations/PGMedicalEducation Regulations2000.aspx. Accessed April 21, 2011.

2. Medical Council of India. Information Desk, College and Course Search. Available from: URL: http://www.mciindia.org/Information Desk/CollegesCoursesSearch.aspx. Accessed April 21, 2011. 